\title{
Assessment of Dysphagia in Acute Stroke Patients by the Gugging Swallowing screen
}

\author{
Samia El Said Bassiouny ${ }^{1 *}$, SafinazNagibAzab ${ }^{2}$, Rasha Hassan Soliman ${ }^{3}$ and Shaimaa Ahmed saleh ${ }^{4}$ \\ ${ }^{1}$ Department of Otorhinolaryngology, Ain Shams University, Egypt \\ ${ }^{2}$ Department of Otorhinolaryngology, Benisuef University, Egypt \\ ${ }^{3}$ Department of Neurology, Benisuef University, Egypt \\ ${ }^{4}$ Department of Otorhinolaryngology, Benisuef University, Egypt
}

Submission: July 21, 2017; Published: August 08, 2017

*Corresponding author: Samia El Said Bassiouny, Department of Otorhinolaryngology, Professor of Phoniatrics, Faculty of Medicine, Ain Shams University, Cairo, Egypt, Tel: 00201224911049; Email: Bassiounys@yahoo.com

\begin{abstract}
Dysphagia is a commonly documented morbidity after stroke. The early detection of dysphagia in patients with acute stroke reduces not only complications but also reduce length of hospital stay, The Gugging Swallowing Screen test is a simple, valid, and reliable test to detect early aspiration as it has high sensitivity and specificity. It is easy, rapid, and suitable noninvasive tool to grade the severity of dysphagia.
\end{abstract}

Keywords: Gugging swallowing screen; Dysphagia; FEES; Stroke; Aspiration pneumonia.

Abbreviations: GUSS: The Gugging Swallowing Screen; FEES: Fiberoptic endoscopic evaluation of swallowing

\section{Introduction}

Swallowing is an organized process that acts automatically with sequential movements involving the tongue, pharyngeal and esophageal muscles [1]. Dysphagia is a dysfunction of swallowing that prevents optimal passage of fluids and/or food from the lips to the stomach, and may leads to life threatening complications such as aspiration, dehydration and malnutrition [2]. Dysphagia may manifest through a series of signs and symptoms, like: mastication disorder, delayed initiation of swallowing, nasal regurgitation, choking, coughing during eating or drinking; pharyngeal globus (sensation of food residue in the throat), diet restriction which in severe cases, leads to: (malnutrition, dehydration, weight loss), increased meal time, loss of appetite; and aspiration pneumonia [3]. Swallowing process is initiated by the cerebral cortex then effected by the swallowing center located at the brain stem, so that brain injury, caused by stroke, leads to disruption of the normal physiology of swallowing, leaving the patient vulnerable to dysphagia and its complications [4].

Dysphagia is present in $43 \%$ to $67 \%$ of acute stroke patients and the incidence of aspiration within the first 5 days ranges from $19.5 \%$ to $42 \%$ [5], so pneumonia in stroke patients is the result of aspiration [6]. Dysphagia screening is the first step in an appropriate management plan, as it reduces risk of developing aspiration pneumonia, and mortality in patients with cerebrovascular accidents like stroke [6]. The Gugging Swallowing Screen, was developed by Trapl et al. [5], is an interesting test as the water swallow test was replaced by a semisolid swallow test, the authors considered semisolids safer than thin liquid. The test was developed based on a study of 50 stroke patients, they underwent, physical assessment of the swallowing function and fiberoptic endoscopic examination of swallowing (FEES) to verify the results of GUSS. The aim of this study was to investigate the sensitivity and specificity of the Gugging Swallowing Screening on Acute stroke patients for the early detection of dysphagic patients to decrease risk of aspiration and pneumonia.

\section{Materials and Methods}

The study included 40 stroke patients from the Phoniatricoutpatient clinic of Ain shams University Hospital and Beni-Suef University Hospital, sex distribution of stroke patients was 23 males (57\%) and 17 female (43\%), Male: Female ratio $=1.4$ : 1 , their age ranged from 41 years -77 years, Mean $61.8 \pm 7.8$ , Median 62.5, (Table 1). The included patients were, stroke patients within the 1 st 2 weeks of illness, at any age or sex, they 
should be conscious alert and can follow directions. The exclusion criteria were uncooperative patient (disturbed conscious level, dementia, global dysphasia) to guarantee cooperation during examination and dysphagic patients of other known cause.

Table 1: Sex and age distribution of patients.

\begin{tabular}{|c|c|}
\hline Distribution of Patients & No (\%) \\
\hline Sex & \\
\hline Male & $17(43 \%)$ \\
\hline Female & $23(57 \%)$ \\
\hline Age & \\
\hline Median & 62.5 \\
\hline Mean \pm SD & $61.8 \pm 7.8$ \\
\hline Range & $41-77$ \\
\hline
\end{tabular}

All patients were subjected to the following protocol of assessment, including clinical assessment, Gugging Swallowing
Screen and FEES examination: The Gugging Swallowing Screen [5] (Appendix A). Before starting the GUSS screen, the phoniatrician should make sure that the patient is able to perceive the tester's face; the textures in front of her/him and the spoon, the patient should sit in bed at a $60^{\circ}$ upright position at least. GUSS composed of 2 parts, the preliminary assessment (indirect swallowing test) and the direct swallowing test, which consists of 3 subtests. GUSS Part 1, The Indirect Swallowing Test, evaluation was performed for, vigilance, voluntary coughing, deglutition of saliva, drooling and voice change. Patients, who were not able to produce enough saliva, were given saliva spray as a substitute. Deglutition is determined by observing an effectual larynx elevation. GUSS Part 2, direct swallowing test, consists of 3 sequentially performed subtests, starting with semisolid, then liquid, and finally solid consistency. The evaluation criteria used in the direct swallowing test were cough, deglutition problem, voice change and drooling.

Appendix A: Gugging swallowing screen (G U S S)

\begin{tabular}{|c|c|c|}
\hline & YES & No \\
\hline Vigilance & \multirow[b]{2}{*}{1} & \multirow[b]{2}{*}{0} \\
\hline $\begin{array}{l}\text { (The patient must be alert for at least } 15 \\
\text { minutes) }\end{array}$ & & \\
\hline Cough and/or Throat Clearing & \multirow[b]{2}{*}{1} & \multirow[b]{2}{*}{0} \\
\hline $\begin{array}{l}\text { (Voluntary cough! Patient should cough or } \\
\text { clear his or her throat twice) }\end{array}$ & & \\
\hline $\begin{array}{l}\text { Saliva Swallow } \\
\end{array}$ & \multirow{5}{*}{$\begin{array}{l}1 \\
0\end{array}$} & \multirow{5}{*}{0} \\
\hline a. Swallowing Successful & & \\
\hline b. Drooling & & \\
\hline c. Voice Change & & \\
\hline $\begin{array}{l}\text { (hoarse, gurgely, coated, weak, choke on own } \\
\text { saliva) }\end{array}$ & & \\
\hline \multirow[t]{3}{*}{ Sum } & -5 & \\
\hline & \multicolumn{2}{|c|}{$1-4$ = Investigate further } \\
\hline & & \\
\hline
\end{tabular}

1.Preliminary Investigation / Indirect Swallowing Test

\begin{tabular}{|c|c|c|c|}
\hline In the following order: & $\begin{array}{c}\text { 1-- } \\
\text { Semisolids }\end{array}$ & $\begin{array}{c}2- \\
\text { Liquids }\end{array}$ & $\begin{array}{c}3- \\
\text { Solids }\end{array}$ \\
\hline Deglutation: & \multirow[t]{5}{*}{0} & \multirow[t]{2}{*}{0} & \multirow[t]{2}{*}{0} \\
\hline Swallowing not possible & & & \\
\hline Swallowing delayed & & \multirow{3}{*}{1} & \multirow{3}{*}{1} \\
\hline$>2$ sec. & & & \\
\hline (Solid textures > $10 \mathrm{sec}$.) & & & \\
\hline Swallowing successful & 2 & 2 & 2 \\
\hline Cough (Involuntary) & \multirow{4}{*}{0} & \multirow{4}{*}{1} & \multirow{4}{*}{0} \\
\hline $\begin{array}{c}\text { (before, during or after } \\
\text { swallowing - until } 3 \text { minutes } \\
\text { later) }\end{array}$ & & & \\
\hline Yes & & & \\
\hline No & & & \\
\hline
\end{tabular}




\begin{tabular}{|c|c|c|c|}
\hline Voice Change & & & \\
\hline $\begin{array}{c}\text { (listen to the voice before and } \\
\text { after swallowing- patient should } \\
\text { speak ",h") } \\
\text { Yes }\end{array}$ & 0 & 0 & 0 \\
No & 1 & 1 & 0 \\
\hline Drooling & 0 & 0 & 1 \\
\hline Yes & 1 & 1 & 5 \\
\hline No & 5 & 5 & $1-4=$ Investigate further \\
\hline Sum & $1-4=$ Investigate further & $1-4=$ Investigate further \\
& $5=$ Continue LIQUID & $5=$ Continue SoLID & $5=$ NORMAL \\
\hline
\end{tabular}

2.Direct Swallowing Test.

\begin{tabular}{|c|c|}
\hline \multicolumn{2}{|c|}{ Summary } \\
\hline Indirect swallowing test & 5 \\
\hline Direct swallowing test & 15 \\
\hline Total & 20 \\
\hline
\end{tabular}

3.Direct and Indirect Swallowing Test.

\begin{tabular}{|c|c|c|c|}
\hline & Results & $\begin{array}{c}\text { Severity } \\
\text { Code }\end{array}$ & Recommendations \\
\hline 20 & $\begin{array}{l}\text { Semisolid / liquid } \\
\text { and solid textures } \\
\text { successful }\end{array}$ & $\begin{array}{c}\text { Slight / No dysphagia } \\
\text { Minimal risk of aspiration }\end{array}$ & $\begin{array}{l}\text { Normal diet } \\
\text { Regular liquids } \\
\text { First time under supervision of the SLT or a trained stroke nurse! }\end{array}$ \\
\hline $19-15$ & $\begin{array}{l}\text { Semisolid and } \\
\text { liquid texture } \\
\text { successful and } \\
\text { solid } \\
\text { unsuccessful }\end{array}$ & $\begin{array}{l}\text { Slight dysphagia with a } \\
\text { low risk of aspiration }\end{array}$ & $\begin{array}{l}\qquad \begin{array}{c}\text { Dysphagie diet (pureed and soft food) } \\
\text { Liquids very slowly - one sip at a time }\end{array} \\
\text { Functional swallowing assessments such as Fiberoptic Endoscopic Evaluation } \\
\text { Swallowing (FEES) or Video fluoroscopic Evaluation of Swallowing (VFES) } \\
\text { Refer to Speech and Language Therapist (SLT) }\end{array}$ \\
\hline $14-10$ & $\begin{array}{l}\text { Semisolid swallow } \\
\text { successful and } \\
\text { liquids } \\
\text { unsuccessful }\end{array}$ & $\begin{array}{c}\text { Moderate dysphagia with } \\
\text { a risk of aspiration }\end{array}$ & $\begin{array}{l}\text { Dysphagia diet beginning with: } \\
\text { Semisolid textures such as baby food and additional parenteral feeding } \\
\text { All liquids must be thickened! } \\
\text { Pills must be crushed and mixed with thick liquid } \\
\text { No liquid medication!! } \\
\text { Further functional swallowing assessments (FEES, VFES) } \\
\text { Refer to Speech and Language Therapist (SLT) } \\
\text { Supplementation with nasogstric tube or parenteral }\end{array}$ \\
\hline $9-0$ & $\begin{array}{l}\text { Preliminary } \\
\text { investigation } \\
\text { unsuccessful or } \\
\text { semisolid swallow } \\
\text { unsuccessful }\end{array}$ & $\begin{array}{l}\text { Severe dysphagia with a } \\
\text { high risk of aspiration }\end{array}$ & $\begin{array}{l}\text { NPO (non per os = nothing by mouth) } \\
\text { Further functional swallowing assessments (FEES, VFES) } \\
\text { Refer to Speech and Language Therapist (SLT) } \\
\text { Supplementation with nasogstric tube or parenteral }\end{array}$ \\
\hline
\end{tabular}

Results 
Semisolid swallowing trial was started by one-half teaspoon of yoghurt followed by 5 more half-teaspoons. The Phoniatrician observed the patient closely after each spoonful. Abort the screening test if 1 of the 4 aspiration signs (cough, deglutition problem, voice change and drooling) is positive. Liquid swallowing trial was started by asking the patient to swallow $3 \mathrm{~mL}$ of water and observe him/her closely while swallowing the first amount. When swallowing is successful, the test is continued with increasing amounts of 5, 10, and $20 \mathrm{~mL}$ of water. A $50 \mathrm{~mL}$ test is the last task for the patient. The patient should drink the $50 \mathrm{~mL}$ as fast as possible. Discontinue the investigation if 1 of the 4 aspiration signs (cough, deglutition problem, voice change and drooling) is positive. Solid swallowing trial, a small piece of dry bread is tried as the first bolus. Then the test is repeated 5 times. Ten seconds is the time limit for a small solid bolus, including the oral preparatory phase and oral voluntary phase.

After swallowing assessment with GUSS, all patients underwent FEES, the type of naso-laryngoscope was Karl-Storz, $1101 \mathrm{RP}$, angle of view $70^{\circ}$, working length $30 \mathrm{~cm}$, and the distal end outer diameter is $3.5 \mathrm{~cm}$. The patient was prepared for the examination with counseling regarding the purpose, risks and benefits, both naris were examined visually and the laryngoscope passed through the most patent nostril without administration of a topical anesthetic or decongestant to the nasal mucosa. The Phoniatrician used two endoscope positions during the FEES, pre-swallow position, the laryngoscope is passed in the inferior meatus just inferior to the inferior turbinate, when the scope is present in the nasopharynx, the velopharyngeal port is viewed adequately then, the patient was asked to dry swallow to assess velopharyngeal competence during swallowing. After that the tip of the laryngoscope is advanced to a position between the tip of the epiglottis and the soft palate, to visualize, base of tongue, valleculae, larynx, and pyriform sinuses, retraction of the base of tongue assessed during dry swallow and repeating of postvocalic /l/ word like 'all', Movement of pharyngeal constrictors and longitudinal muscles, evaluated during phonation of strained loud high /ee/ and repeated /ee/.

Laryngeal functions, the most important laryngeal function is airway protection assessed by asking the patient to hold his breath lightly to assess true vocal folds closure, and then hold his breath tightly to assess false vocal folds closure. Abduction and adduction of true vocal folds, assessed during respiration and phonation. Post-swallow position, following the swallowing, the phoniatrician advanced the laryngoscope into the laryngeal vestibule to visualize the larynx, sub glottis, and anterior tracheal wall, to detect laryngeal penetration and/or aspiration. Following this close inspection, the laryngoscope was retracted to the pre-swallow position to detect residue and prepare for next bolus. Swallowing assessment, done by three different consistencies: Semi-solid consistency, first $1 / 2$ teaspoon of yoghurt colored green with food dye (pudding-like consistency) was administrated, if there was no symptoms 1 to 2 tablespoons were applied, then assessment was done. Liquid consistency, 3 , $5,10,20 \mathrm{ml}$ of water were sequentially assessed, if there are no symptoms of aspiration, continue with $50 \mathrm{ml}$ water.

Solid consistency, dry bread or biscuits, which were dipped in green colored liquid. To compare the results of FEES with Gugging swallow screen, the residue was graded according to the Penetration Aspiration Scale (PAS) of Rosenbek et. al [7] (Table 2). The highest score achieved in either the semisolid or the fluid trial was taken as the final score, patients their score range was (1-2) were considered normal, while those their score range was (3-8) were considered dysphagic, for aspiration risk, the PAS cutoff point was between 4 and 5 at the stage of laryngeal penetration of material) liquid or semisolid) reaching to the vocal folds. The ability to eject this material from the airway was therefore the crucial characteristic for risk of aspiration. The GUSS cutoff point for aspiration risk was chosen between the total scores of 14 and 15.

Table 2: Rosenbeck's Penetration Aspiration Scale.

\begin{tabular}{|c|c|c|}
\hline $\begin{array}{c}\text { Neither penetration } \\
\text { Nor aspiration }\end{array}$ & 1 & Material does not enter airway. \\
\hline \multirow{4}{*}{ Penetration } & 2 & $\begin{array}{l}\text { Material enters airway, but remains above } \\
\text { vocal folds; Ejected from airway; no stasis. }\end{array}$ \\
\hline & 3 & $\begin{array}{l}\text { Material remains above vocal folds; visible } \\
\text { stasis remains. }\end{array}$ \\
\hline & 4 & $\begin{array}{l}\text { Material contacts vocal folds, but is ejected; } \\
\text { no stasis. }\end{array}$ \\
\hline & 5 & $\begin{array}{l}\text { Material contacts vocal folds, and is not } \\
\text { ejected; visible stasis remains. }\end{array}$ \\
\hline \multirow[b]{2}{*}{ Aspiration } & 6 & $\begin{array}{l}\text { Material passes glottis, but is ejected from } \\
\text { airway; No visible subglottic stasis. }\end{array}$ \\
\hline & 7 & $\begin{array}{l}\text { Material passes glottis, but is not ejected } \\
\text { from airway; visible Subglottic stasis despite } \\
\text { patient's response. }\end{array}$ \\
\hline
\end{tabular}




\section{Global Journal of Otolaryngology}

\section{Results}

This study included 40 stroke patients, according to PAS, 22 patients (55\%) were dysphagic, 18 (45\%) patients were non dysphagic, 17 female patients (43\%) and 23 male patient (57\%), dysphagic patients distribution: 14 male patients (35\%), 8 female patients (20\%), Nondysphagic patient distribution: 15 male patients (37.5\%), 3 female patients $(7.5 \%)$ the main cause of stroke was infarction 36 patient (90\%), while only 4 patients had hemorrhagic stroke (10\%), site of lesion was supratentorial
Material passes glottis, and is not ejected; visible subglottic stasis; Absent patient response.

Table 3: Demographic data of the patients.

\begin{tabular}{|c|c|c|c|}
\hline & Overall study population & No dysphagia & Dysphagia \\
\hline No. of patients & 40 & $18(45 \%)$ & $22(55 \%)$ \\
\hline Female & $17(43 \%)$ & $3(7.5 \%)$ & $15(37.5 \%)$ \\
\hline Male & $23(57 \%)$ & & $14(35 \%)$ \\
\hline Type of stroke & $4(10 \%)$ & $1(25 \%)$ & $3(75 \%)$ \\
\hline Haemorrhagic & $36(90 \%)$ & $17(47 \%)$ & $19(53 \%)$ \\
\hline Infarction & & & $18(47 \%)$ \\
\hline Location of stroke & $38(95 \%)$ & None & $20(53 \%)$ \\
\hline Supra-tentorial & $2(5 \%)$ & $2(100 \%)$ \\
\hline Infra-tentorial & & & \\
\hline
\end{tabular}

Table 4: Distribution of studied cases according to age (years).

\begin{tabular}{|c|c|c|c|}
\hline Age group & & No. & $\%$ \\
\hline Group 1 & $40-49$ & 3 & $7 \%$ \\
\hline Group 2 & 50-59 & 11 & $28 \%$ \\
\hline Group 3 & $60-69$ & 20 & $50 \%$ \\
\hline Group 4 & $70+$ & 6 & $15 \%$ \\
\hline \multicolumn{2}{|c|}{ Total } & \multicolumn{2}{|c|}{40} \\
\hline \multicolumn{2}{|c|}{ Range } & \multicolumn{2}{|c|}{$41-77$} \\
\hline \multicolumn{2}{|c|}{ Mean } & \multicolumn{2}{|c|}{61.8} \\
\hline \multicolumn{2}{|c|}{$\pm \mathrm{SD}$} & \multicolumn{2}{|c|}{7.8} \\
\hline
\end{tabular}

Table 5: The Gugging swallowing screen results.

\begin{tabular}{|c|c|c|c|}
\hline Results & Severity code & Patient No. (\%) & Diet recommendation \\
\hline 20 & $\begin{array}{c}\text { Slight / No dysphagia Minimal } \\
\text { risk of aspiration }\end{array}$ & Normal \\
\hline $15-19$ & $\begin{array}{c}\text { Slight dysphagia with a low risk of } \\
\text { aspiration }\end{array}$ & $8(40 \%)$ & Dysphagic diet \\
\hline $10-14$ & $\begin{array}{c}\text { Moderate dysphagia with a risk of } \\
\text { aspiration }\end{array}$ & $6(15 \%)$ & NPO diet \\
\hline $0-9$ & $\begin{array}{c}\text { Severe dysphagia with a high risk } \\
\text { of aspiration }\end{array}$ & \\
\hline
\end{tabular}




\section{Global Journal of Otolaryngology}

Comparing the results, of GUSS and FEES examination revealed that, 16 patients had aspiration risk by GUSS, while 15 patients had aspiration risk by FEES, 24 patients had no aspiration risk by GUSS, while 25 patients had no aspiration risk diagnosed by FEES, sensitivity of GUSS was $93.8 \%$, specificity was $96.1 \%$, negative predictive value was $96.2 \%$, and positive predictive value was 93.7\%, prevalence 37\% (Table 6). According to PAS, 7 patients had aspiration, 1 patient (14\%) during semisolid swallowing, and 1 patient (14\%) during $5 \mathrm{ml}$ liquid swallowing, 2 patients (28\%) during $20 \mathrm{ml}$ liquid swallowing, 3 patient (14\%) during $50 \mathrm{ml}$ liquid swallowing (Table 7).

Table 5: The Gugging swallowing screen results.

Table 6: Comparison between GUSS results and FEES results.

\begin{tabular}{|c|c|c|c|c|}
\hline & GUSS Results & \% & FEES Results & \% \\
\hline Aspiration risk & 16 & $40 \%$ & 15 & $37 \%$ \\
\hline No aspiration risk & 24 & $60 \%$ & 25 & Prevalence \\
\hline Sensitivity & Specificity & NPV & $93.7 \%$ & $37 \%$ \\
\hline $93.8 \%$ & $96.1 \%$ & $96.2 \%$ & & \\
\hline
\end{tabular}

NPV: Negative predictive value

PPV: Positive predictive value

Table 7: Relation between food consistency and aspiration.

\begin{tabular}{|c|c|c|}
\hline Food consistency & Aspirated patients, PAS (6-8) & Percentage \\
\hline Semisolid & 1 & $14 \%$ \\
\hline \multicolumn{3}{|l|}{ Liquid } \\
\hline $3 \mathrm{ml}$ & None & None \\
\hline $5 \mathrm{ml}$ & 1 & $14 \%$ \\
\hline $10 \mathrm{ml}$ & None & None \\
\hline $20 \mathrm{ml}$ & 2 & $28 \%$ \\
\hline $50 \mathrm{ml}$ & 3 & $44 \%$ \\
\hline Solid & None & None \\
\hline
\end{tabular}

\section{Discussion}

This study included 40 stroke patients their age ranged between (41-77 years), According to the latest WHO data published in 2015, life expectancy in Egypt is: 68.8 years for males and 73.2 years for females, the clinical characteristics of Egyptian stroke patients are generally similar to those in other populations, exceptions may include the higher prevalence of vascular risk factors and a younger age of stroke patients due to high prevalence of rheumatic heart disease [8]. About $65 \%$ of stroke patients, were above 60 years, dysphagia is a growing health concern in aging population, this results in agreement with Sura et al. [9] who found that, age-related changes in swallowing physiology as well as age-related diseases such as stroke are predisposing factors for dysphagia in the elderly population.

The incidence of stroke, the frequency and factors associated to dysphagia after a stroke is variable. For example, the frequency of dysphasia after a stroke is ranged between $14 \%$ and $94 \%$ among the different studies [10-14], 53\% of patients with supratentorial lesion were dysphagic, while $100 \%$ of patients with infratentorial lesion were dysphagic. Infratentorial strokes happens less frequently than supratentorial strokes but leads to the greatest swallowing problems as they can affect sensation of the mouth, cheek, and tongue, timing of the initiation of the pharyngeal swallow, laryngeal elevation, closure of the glottis, and cricopharyngeal relaxation [15]. GUSS is classified into 4 severity codes, with this gradation; the extent of risk of aspiration as well as the severity of dysphagia can be assessed [5]. Therefore, this system is advantageous to other bedside screening tests that were restricted to presence or absence of dysphagia and/or aspiration [16]. The GUSS test has high sensitivity (93.7\%) and high specificity (92.5\%). Other studies investigated GUSS sensitivity and specificity.

Trapl et al. [5], assessed 50 acute-stroke patients prospectively, and found that GUSS has 100\% sensitivity, $69 \%$ specificity, and $100 \%$ negative predictive value; this results coincide with results of this study. Warnecke et al. [17] in a prospective, double-blind design, the GUSS was validated 


\section{Global Journal of Otolaryngology}

with the Fiber optic Endoscopic Evaluation of Swallowing scale. A total of 100 patients with acute stroke were evaluated consecutively at a mean 1.7 -2.2 days after stroke. With the GUSS cut-off value of 14 points, the GUSS screened aspiration risk with a high sensitivity $96.5 \%$ and $55.8 \%$ specificity, specificity is much lower than found by this study.

Aspiration happened more frequently with liquid bolus than semi-solid and solid bolus, this results are consistent with Warnecke et al. [18], who observed the swallowing process with various food consistencies in patients with progressive supra-nuclear palsy and Parkinsonism. In both patients groups, penetration and/ or aspiration observed more frequently for liquid consistency and was occurred significantly less frequently for pasty and solid food consistency. Allen et al. [19], assessed swallowing by barium swallow and recorded episodes of penetration/aspiration by bolus size, age and food consistency. The study included healthy adult volunteers without neurological diseases or dysphagia. Penetration was observed in $11.4 \%$ of healthy individuals, and also was more common with liquid bolus. Penetration was significantly high, but did not constitute a threat.

Kuhlemeier et al. [20], examined the rates of aspiration and pharyngeal retention in 190 dysphagic patients given thin liquid (apple juice) and thick liquid (apricot nectar) delivered by teaspoon and cup and ultra-thick (pudding-like) liquid delivered by teaspoon. Each patient was tested with each of the bolus/ delivery method combinations. Penetration and aspiration were more frequent with thin fluids than thick fluids, and more frequent when cup is used for drinking, this means that penetration and aspiration, not only affected by consistency but also volume delivered by bolus, this results are consistent with the results of this study. Pharyngeal residue more likely happens with thick consistency and this predisposes the patient to post swallow aspiration.

\section{Conclusion}

The GUSS test is simple, valid, and reliable test to early detect dysphagia and aspiration as it has high sensitivity and specificity. It is very easy, rapid, and suitable non-invasive tool to grade the severity of dysphagia.

\section{References}

1. Lee SU, Park JH, Kim HJ, Deriu F, Kim JS, et al. (2014) Swallowinginduced vertigo and downbeat nystagmus. J neurol 261(12): 2457 2459.

2. Vallons KJ, Helmens HJ, Oudhuis AA CM (2015) Effect of human saliva on the consistency of thickened drinks for individuals with dysphagia. Int J Lang Commun Disord 50(2): 165-175.
3. Karkos PD, Papouliakos S, Karkos CD, Theochari EG (2009) Current evaluation of the dysphagic patient. Hippokratia 13(3): 141-146.

4. Power ML, Fraser CH, Hobson A, Singh S, Tyrrell P, et al. (2006) Evaluating oral stimulation as a treatment for dysphagia after stroke. Dysphagia 21(1): 49-55.

5. Trapl M, Enderle P, Nowotny M, Teuschl Y, Matz K, Dachenhausen A, et al. (2007) Dysphagia bedside screening for acute-stroke patients. Stroke 38(11): 2948-2952.

6. Martino R, Foley N, Bhogal S, Diamant N, Speechley M, et al. (2005) Dysphagia after stroke incidence, diagnosis, and pulmonary complications. stroke 36(12), pp.2756-2763.

7. Rosenbek J C, Robbins J, Roecker E V, Coyle JL, Woods JL, et al. (1996) A penetration-Aspiration Scale. Dysphagia 11(2):93-98.

8. Abd-Allah F, Moustafa RR (2014) Burden of stroke in Egypt: current status and opportunities. Int J Stroke 9(8): 1105-1108.

9. Sura L, Madhavan A, Carnaby G, Crary MA (2012) Dysphagia in the elderly: management and nutritional considerations. Clin Interv Aging 7(7): 287-298.

10. Jean A (2001) Brain stem control of swallowing: neuronal network and cellular mechanisms. Physiol Rev 81(2): 929-969.

11. Dziewas R, Sörös P, Ishii R, Chau W, Henningsen H, et al. (2003) Neuroimaging evidence for cortical involvement in the preparation and in the act of swallowing. Neuroimage 20(1): 135-144.

12.Xerez DR, Carvalho YSV, Costa MMB (2004) Clinical and videofluoroscopic study of dysphagia in the subacute stage of stroke. Radiol Bras 37(1): 9-14.

13. Paciaroni M, Mazzotta G, Corea F, Caso V, Venti M, et al. (2004) Dysphagia following stroke. European neurology 51(3): 162-167.

14. Mourão AM, Lemos SMA, Almeida EO, Vicente LCC, Teixeira, et al. (2016) Frequency and factors associated with dysphagia in stroke. CoDAS 28(1): 66-70.

15. Ertekin C, Aydogdu I, Tarlaci S, Turman AB, Kiylioglu N, et al. (2000) Mechanisms of dysphagia in suprabulbar palsy with lacunar infarct. Stroke 31(6): 1370-1376

16. Crary MA, Mann GDC, Groher ME (2005) Initial psychometric assessment of a functional oral intake scale for dysphagia in stroke patients. Arch Phys Med Rehabil 86(8): 1516-1520.

17. Warnecke T, Im S, Kaiser C, Hamacher C, Oelenberg S, Dziewas R, et al. (2017) Aspiration and dysphagia screening in acute stroke-the Gugging Swallowing Screen revisited. Eur J Neurol 24(4): 594-601.

18. Warnecke T, Oelenberg S, Teismann I, Hamacher C, Lohmann H, et al. (2010) Endoscopic characteristics and levodopa responsiveness of swallowing function in progressive supranuclear palsy. Move disord 25(9): 1239-1245.

19. Allen JE, White CJ, Leonard Rj, Belafsky PC (2010) Prevalence of penetration and aspiration on videofluoroscopy in normal individuals without dysphagia. Otolaryngol Head Neck Surg 142(2): 208-213.

20. Kuhlemeier KV, Palmer JB, Rosenberg D (2001) Effect of liquid bolus consistency and delivery method on aspiration and pharyngeal retention in dysphagia patients. Dysphagia 16(2): 119-122. 
Your next submission with Juniper Publishers will reach you the below assets

- Quality Editorial service

- Swift Peer Review

- Reprints availability

- E-prints Service

- Manuscript Podcast for convenient understanding

- Global attainment for your research

- Manuscript accessibility in different formats ( Pdf, E-pub, Full Text, Audio)

- Unceasing customer service

Track the below URL for one-step submission https://juniperpublishers.com/online-submission.php 